\title{
Critical thinking and an ethical approach to studying History - the case for ICT
}

\author{
Alnazz Kassam \\ Toronto District School Board, 8 Burnt Bark Drive, Scarborough, Canada M1 V3 J8
}

alnkassam@yahoo.com,akassam@oise.utoronto.ca

Key words: Culture, ICT, Justice, Society

Abstract: In this paper it is argued that the introduction of the Internet into the classroom provides a unique forum for the cultures of the world to communicate with each other, arrive at a new understanding between each other and be able to redefine views of how knowledge is formed. The paper will present two alternate views of critical thinking - the orthodox and the second cycle - and their connection to historical inquiry. The paper will show how these two approaches to critical thinking are reflected in an Internet project, which allowed eight Canadian classrooms to study history from a First Nations (indigenous peoples) perspective.

\section{INTRODUCTION}

The research data for this paper stemmed from the Other Story project (funded by the Ontario Ministry of Education from 1993 to 1995). This was designed to bring the perspective of the "other" into the classroom. The project argued that in textbooks and through the media, cultures of the world are often reflected in ways that their members might not agree with.

In this paper I will show how the project, in offering an opportunity to explore and reflect, helped re-define our approach to education, to the study of history and to critical thinking.

The original version of this chapter was revised: The copyright line was incorrect. This has been corrected. The Erratum to this chapter is available at DOI: 10.1007/978-0-387-35663-1_34 


\section{CRITICAL THINKING AS GOOD THINKING}

Critical thinking, in recent years, has acquired popularity as a way of getting students to be independent thinkers able to function in a democracy.

"Most orthodox theoretical accounts of critical thinking argue that the ultimate function of good thinking is to distinguish between justified and unjustified claims of beliefs. This is done by applying the rules and techniques of formal and informal logic to propositional expressions in order to determine if their statements are true and their arguments valid or sound. Justified claims and beliefs, then, reduce to those that stand up to the rigorous tests of logical analysis, while unjustified ones, obviously do not. A good thinker, consequently, is one who is skilled in the manipulation of logical criteria and who willingly abides by the evaluative conclusions it generates." (Walters 1994)

Giroux, however, considered two major assumptions were missing from orthodox definitions of critical thinking - the relationship between theory and facts and that knowledge cannot be separated from human interests, norms and values.

"How information is selected, arranged, and sequenced to construct a picture of contemporary or historical reality is more than a cognitive operation; it is also a process intimately connected to the beliefs and values that guide one's life." (Giroux 1994)

Obviously historical analysis cannot be dismissed as value-free or as a simple explanation of "what happened". In the choice of facts and the framework provided in their interpretation we make decisions about how we interpret the world and our place in it as players.

\section{PROJECT OVERVIEW AND ACTIVITY}

The Other Story was a research project to develop curriculum for inter-cultural understanding through a critical inquiry, issues-oriented approach. It combined classroom-based discussion and an on-line conference linking schools throughout Canada to students, teachers and adherents of the culture being studied. The project's most important objective was to study cultures from their own perspective. It was envisaged that through on-line activity the students would develop a deeper, more sophisticated and less media-bound understanding of different cultures. 
In Spring 1995, eight Grade 8 classrooms, including two from First Nations schools, participated in an Internet conference "First Nations Peoples: The Untold Story". This examined a significant event in Canadian history and presented it to students both from the conventional textbook view and from the perspective of the First Nations people. Students read and responded to a story written by two First Nations authors about Mistahimaskwa (Big Bear) who defied the encroaching Canadian government forces who wished to occupy and take over his people's land. Students were encouraged to look for information in other resources and consider: Have we been exposed to the First Nations viewpoint before? Why or why not? What does this tell us about our history and about ourselves?

Responses from each classroom were shared on a listserv. One project objective was to encourage reflection - have we as teachers, students and adherents of the various cultures learned anything from this exchange of experiences? How does this portrayal of indigenous and non-indigenous peoples affect our relationship? How can we use this learning experience to affect a change in the relationship between us?

This paper focuses on the student responses from three very different schools - A. S. Dawson, Shoreside and Lakeside.

\subsection{A. S. Dawson's Participation in the project}

This is a suburban school in a large metropolitan city. It stands in the middle of a first generation immigrant neighbourhood close to a wealthy residential area. The students are hard-working and well above their grade level in reading and computational skills. They introduced themselves clearly confident of their strengths and their ability to see the "other" view:

"As students, we have been influenced in many ways. We watch videos and take trips to educational areas. These help expand our thoughts. By having these privileges, it helps us think more clearly and assists us in deciphering what's right and wrong. This enables us to see the Native's aspect of the situation."

\subsection{A. S. Dawson and Mistahimaskwa's story}

The story of Mistahimaskwa, is the story of a Cree chief, who, during the 1870 's, resisted treaty agreements with the Canadian government and attempted to form a united front against government appropriation of aboriginal land (Fletcher 1995). Mistahimaskwa does not succeed in keeping 
his land. In fact his attempts at compromise and his treaty arrangements with the government result in betrayal. This story is very much a reflection of Canada's history - who we are and where we have come from.

The story was delivered to the students on-line and their first response was:

"When we first read the story, we had very strong and intense feelings about it. We felt very sympathetic towards the Cree and their chief, and we felt very outraged towards the Europeans who tried to take away the land which the Cree lived on."

The students noted the wanton killing of the buffalo by the Europeans, the "heartless and ignorant" snatching away of the Cree land, the fact that the Europeans didn't uphold the treaty and the lack of understanding they betrayed toward the Cree culture:

"If the Europeans had tried to put themselves in the Cree position, history probably would have changed for the better. We feel the Europeans acted unfairly towards the Cree, treating them as if they were inferior."

Initial analysis of the language used in this passage displays two examples of bias. Firstly, students do not believe the perpetrators of this injustice are the Canadian government. They identify them as Europeans. From this story and their study of history, the students should be well aware that the Canadian government sanctioned land acquisition. The Canadian government dispatched 8000 troops to vanquish Mistahimaskwa's several hundred tired, hungry men. The students didn't notice this. Distinguishing between European and Canadian is an attempt to distance the actions of the perpetrators from the students' own government and thus from themselves (Fletcher 1995).

The second example of bias is the underlying tone that the Europeans could not be "blamed" for what happened because they did not "understand" the other culture - if they had not perceived the Cree to be inferior, they would not have treated them in this manner. The greed and injustice of the situation is downplayed - a refusal to acknowledge responsibility and guilt on the part of one's government.

After examining other resources the students commented:

"We compared the story from the text book and the story by Dion and Fletcher. Some similarities mentioned in both stories included the way the native Indians were acknowledged as poor and starving from the lack of buffalo. Surprisingly, the textbooks also looked at the grievances the natives 
had. The location of the battles specified in each story was also identical. Both mentioned that Big Bear was tried and found guilty of the deaths caused by his warriors. The similarities the stories shared were basically the clean cut facts."

The most important conclusion the students reached was the determination of which text was more accurate. This satisfies the first approach to critical thinking - examination of the logic of the arguments and the verity of the facts presented by both parties. The students identified the similarities between the texts as being the clear-cut facts. Facts can never stand alone - in choosing the facts to include in their version of events historians from both cultural groups made choices. The facts, rather than being neutral and value-free, become in and of themselves an extension of the historians' perspective and interpretation (Carr 1972). For these students, factual analysis is important - the emotional response of the Cree is not recognised for what it is - the unfairness of the situation.

Susan Fletcher was interested in the students' interpretation of the event in what they thought it told them about themselves as human beings, as Canadians. She felt they couldn't complete this process until they examined the interpretation of the event from both perspectives - "those who did it and who it was done to". The students, in avoiding the question of what happened in the larger context of whether it was right that it should have happened also avoided bringing themselves and their own positions into the story. In understanding history from the first critical thinking perspective of logic, they avoid the larger question of whether the government acted fairly and the question of how the historians interpreted this event.

\subsection{Shoreside's students and Mistahimaskwa's story}

These students interpreted the same story in a totally different way which led to different insights. After comparing the story with what they found in their books they commented:

" 'the Cree killed nine whites at Frog Lake, burned Ft. Pitt, and were defeated at Loon Lake'. The article in the encyclopaedia does not include the fact that eight thousand government troops were sent after them. We think that one reason this was not mentioned was because the author of the article did not want to make the Canadian government look bad."

Here students are looking at the historians' "intention" and bias. Only some facts are reported so that the Canadian government is not portrayed as 
evil. This is a form of critical thinking that goes beyond consideration of the given facts. The students then go beyond motive for interpretation of how the vocabulary and images one uses affect how one views events and people.

"In the encyclopaedia "Encarta '95", a brief article on the Cree Indians states that they practised cannibalism in times of hardship. Cannibalism is one of the quick reference words that shows up 'highlighted'!"

The students are beginning to understand the use of vocabulary to represent reality. They realise that linking "cannibalism", an entirely unjustified connection, will affect the way that the Cree are perceived. As they indulge in criticism and in historical analysis of this order they are becoming historians in their own right - no longer accepting history as mere physical events but rather as explanations and interpretations of past events by the historians of their text books. Their intellectual development is illustrated by this response:

"We now see language has a big impact on us and different words, even if they mean the same thing, can give a whole new meaning to a statement. We now know not to believe just one account. Depending on who wrote the account seems to colour what facts are recorded or not recorded."

I would argue that by juxtaposing the text of the textbook, the encyclopaedia and the field visit with the text of the "other", fresh vistas of criticism are revealed. Students begin to question why they have never seen this perspective before.

"Recently our class went to Fort York and stayed overnight in one of the blockhouses. When we looked through the books we learned the views of the soldiers, the officers and Mrs. Simcoe. At no time did we read about or hear from the Fort York interpretative staff what the native point of view was. It's like this in many historic accounts in our books. We were wondering if there was a website or e-mail address where we could get more information."

These students are beginning to move away from the textbooks alone to what their own society provides as the official history of the relationship between the two peoples. They're beginning to see ICT as a possible source for information. They are also beginning to question formal knowledge - the knowledge of their own society and whether it portrays what really happened. 


\subsection{Lakeside School and the Story of Mistahimaskwa}

When we meet the Lakeside students we begin to understand that critical thinking cannot be part of history until one understands the impact of history on a people (especially people without power and subject to the whim and will of a sovereign government). This is a First Nations school in a small town in Northern Manitoba. The students introduced themselves:

"We are all in grade 8 . There are 23 students: 11 boys and 12 girls. We live in Lakeside, Manitoba. It has about 1000 people, three stores, one cafe, and one small motel. Languages spoken are Cree and English. In our recent past (mid 1970s) Manitoba Hydro flooded the lake and river system we live on. Our entire community was moved to higher ground. Our old homes were burned and the fishing industry was devastated. Our people are still recovering from the disaster."

They identified closely with the story of Mistahimaskwa.

"The story makes me feel sorry and angry at the same time. Sorry for the people whose lives were being destroyed and changing the way they've lived for years, because they really had no choice. Angry because those people whose lives were being destroyed are a part of me and I am a part of them. Today things like that are still happening. It was sad because they tried to accept the government's promises but they were not honoured until they lost their temper and killed a lot of people. The government over reacted and sent 8000 people to capture 200 of Mistahimaskwa's people."

Two powerful issues emerge from this interpretation of the story. Firstly, it is their story. They cannot help but identify with the feeling of fear, hunger and loss of one's land, culture and heritage - issues of objectivity and impartiality are secondary. The second related issue is that the oppression is continuing to happen to them today. Participation of the Cree students should bring alive to non-First Nations students the political importance of the story of Mistahimaskwa. This political perspective is present in all historical analysis of events that involve peoples of disparate powers.

The story of Mistahimaskwa cannot remain the historical analysis of an event - an impartial, objective reporting of "what happened". In its interpretation lies the explanation of what Canada was and, through the story of the students at Lakeside, the interpretation of what Canada continues to be today. This interpretation cannot be impartial and objective - like all other history it has a moral dimension. In that context the story as told by the victim becomes critical. Critical thinking is impossible until and unless you 
juxtapose the view of the dominant group with the view of the "other". The whole story cannot emerge until both stories are told. It is in placing oneself as part of this history, in critically examining one's position and identity within this story that true critical thinking can take place.

\section{CONCLUSION}

How do we analyse the Lakeside students' participation in the re-creation of this historical event? I believe that in the listening and in the creation of the audience for the stories of the other through ICT, we are providing a new context for understanding of the other and also of ourselves. History is not the history of the dominant group - it is the history of the relationship created by that domination. We cannot understand that domination unless we see it from the perspectives of both dominated and dominator. The Internet provides a unique environment to juxtapose these two realities providing more complexity to one's acquisition of knowledge and one's critical analysis. This juxtaposition - of the story of the "other" with the "official" version - brings deeper understanding of critical thinking. This interpretation of critical thinking goes beyond objectivity but acknowledges that when human beings explain events they make meaning of them. When you have two contradictory interpretations of one event - especially an event that involves injustice - then true critical thinking will involve debate on one's place in the carrying out of this injustice. I believe that ICT provides a unique forum for multiple perspectives and for egalitarian debate.

\section{REFERENCES}

Carr, E.H. (1972) The Historian and His Facts. In Teaching History in Canada, G. Milburn (ed.), McGraw-Hill Ryerson, Toronto.

Fletcher, S. (1996) I never realized how much I didn't know, Sharing the Story of Mistahimaskwa with Intermediate Students on the Internet. Unpublished paper.

Giroux, H. A. (1994) Toward a Pedagogy of Critical thinking. In Re-thinking Reason: New Perspectives in Critical thinking, K. S. Walters (ed.), State University of New York Press, New York.

Walters, K. S. (ed.) (1994) Re-thinking Reason: New Perspectives in Critical Thinking. State University of New York Press, New York. 